\title{
ESPAÇO ESCOLAR E TRANSFORMAÇÕES NA PAISAGEM: UMA EXPERIÊNCIA DESENVOLVIDA NO FORMATO REMOTO EM UMA ESCOLA PÚBLICA DE SÃO BENTO/PB
}

\author{
Elaine Cristina de Medeiros Pereira ${ }^{1}$, Tânia Cristina Meira Garcia ${ }^{2}$
}

\begin{abstract}
${ }^{1}$ Mestranda do Programa de pós-graduação em Geografia - GEOPROF - CERES da Universidade Federal do Rio Grande do Norte - UFRN. E-mail: elaineufrn@gmail.com. ORCID ID: https://orcid.org/0000-0001-8329-9113.

2 Professora adjunta da Universidade Federal do Rio Grande do Norte - UFRN. E-mail: tania_cristina2005@yahoo.com.br. ORCID ID: https://orcid.org/0000-0002-5488-3684.
\end{abstract}

Artigo recebido em 09/09/2020 e aceito em 06/04/2021

\begin{abstract}
RESUMO
As mudanças trazidas pelo COVID-19, desencadeou na adequação instantânea da vivência diária do espaço escolar. Por esse motivo, escolas e professores tiveram que buscar introduzir em sua rotina, novas estratégias didático/pedagógicas que viessem com o propósito de atender a essa realidade que envolve a suspensão temporária das aulas presenciais. Nesse sentido, a investigação proposta versa sobre as experiências e reflexões adquiridas pela execução de uma proposta didática, planejada para o ensino remoto e ancorada nos aspectos didáticos/pedagógicos do modelo híbrido, tendo como base, o conteúdo curricular da disciplina de Geografia para o $3^{\circ}$ ano do Ensino Fundamental, Anos Iniciais. Portanto, organizar uma atividade didática com estes aspectos, possibilitou autonomia para o aluno em relação ao seu processo de aprendizagem e contribuiu para a reflexão do professor em relação a sua prática e a importância de se presar por um planejamento didático flexível, tendo como objetivo, o progresso individual de cada educando.
\end{abstract}

Palavras-chave: Ensino Remoto; Modelo Híbrido; Geografia; processo de aprendizagem. 


\title{
SCHOOL SPACE AND LANDSCAPE TRANSFORMATION: AN EXPERIENCE DEVELOPED IN REMOTE FORMAT IN A PUBLIC SCHOOL IN SÃO BENTO / PB
}

\begin{abstract}
The changes brought about by COVID-19, triggered the instant adaptation of the daily experience of the school space. For this reason, schools and teachers had to seek to introduce in their routine, new didactic / pedagogical strategies that came with the purpose of meeting this reality that involves the temporary suspension of face-to-face classes. In this sense, the proposed investigation deals with the experiences and reflections acquired by the execution of a didactic proposal, planned for remote teaching and anchored in the didactic / pedagogical aspects of the hybrid model, based on the curricular content of the Geography discipline for the 3rd year of Elementary School, Early Years. therefore, organizing a didactic activity with these aspects, allowed the student autonomy in relation to his learning process and contributed to the reflection of the teacher in relation to his practice and the importance of holding on to a flexible didactic planning, having as objective, the individual progress of each student.
\end{abstract}

Keywords: Remote Education. Hybrid Teaching. Geography. learning process.

\section{TRANSFORMACIÓN DEL ESPACIO ESCOLAR Y PAISAJE: UNA EXPERIENCIA DESARROLLADA EN FORMATO REMOTO EN UNA ESCUELA PÚBLICA DE SÃO BENTO / PB}

RESUMEN: Los cambios provocados por COVID-19, desencadenaron la adaptación instantánea de la experiencia cotidiana del espacio escolar. Por ello, las escuelas y los docentes debieron buscar introducir en su rutina, nuevas estrategias didácticas / pedagógicas que vinieron con el propósito de atender esta realidad que implica la suspensión temporal de las clases presenciales. En este sentido, la investigación propuesta aborda las experiencias y reflexiones adquiridas por la ejecución de una propuesta didáctica, planificada para la enseñanza a distancia y anclada en los aspectos didáctico / pedagógico del modelo híbrido, a partir de los contenidos curriculares de la disciplina de Geografía para la $3^{\circ}$ año de Primaria, Early Years. por tanto, organizar una actividad didáctica con estos aspectos, permitió al alumno autonomía en relación a su proceso de aprendizaje y contribuyó a la reflexión del docente en relación a su práctica y la importancia de aferrarse a una planificación didáctica flexible, teniendo como objetivo, la progreso individual de cada alumno.

Palabras Clave: Educación Remota; Enseñanza híbrida; Geografía; proceso de aprendizaje. 


\section{INTRODUÇÃO}

As mudanças trazidas pelo período de pandemia, fez com que a vivência diária nas instituições educacionais passasse por adequações instantâneas. Por esse motivo, o espaço escolar mediante as determinações das instituições de ensino teve que buscar introduzir em sua rotina, novos métodos e práticas de ensino que viessem a atender a essa realidade.

O ensino remoto emergencial, adotado por instituições desde a educação básica, até as universidades, foi pensado como uma estratégia para amenizar os prejuízos trazidos pela pandemia do novo coronavírus. Essa realidade tem sido desafiadora em virtude da exclusão digital decorrente do país para muitos profissionais, pois nem todos possuem domínio em relação ao uso das tecnologias digitais e sua introdução para o desenvolvimento das aulas.

Partindo disso, a disciplina Tecnologia, Informação e Comunicação e Ensino de Geografia, vinculada do Programa de Pós-Graduação em Geografia - Mestrado Profissional (GEOPROF), oportunizou aos educandos matriculados, conhecer sobre propostas metodológicas inovadores de ensino e as tecnologias digitais, como estratégias para serem colocadas em prática na sala de aula. Dessa forma, ao concluir a discussão teórica dos conteúdos trabalhados nesse componente curricular, os estudantes tiveram a oportunidade de vivenciar a experiência docente de mediar o processo de ensino-aprendizagem, no modelo remoto, a partir dos procedimentos metodológicos estudados e com isso tiveram a oportunidade de perceber a viabilidade de tal processo, mesmo sabendo que nenhum tipo de aparato tecnológico substitui as aulas presenciais.

Portanto, a investigação proposta versa sobre as experiências e reflexões adquiridas pela execução de uma proposta didática, planejada para o ensino remoto e ancorada nos procedimentos teórico-metodológicos do modelo híbrido, tendo como base, o conteúdo curricular da disciplina de Geografia para o $3^{\circ}$ ano do Ensino Fundamental, Anos Iniciais.

Assim, a sequência didática "A paisagem: elementos e mudanças”, foi organizada com o objetivo de levar ao educando entender o conceito de paisagem, identificar os elementos naturais e culturais existentes, bem como, as mudanças e permanências ocorridas ao longo do tempo. Para isso, delimitou como questão orientadora: Quais os processos naturais e históricos colaboram para as mudanças da paisagem no seu lugar de vivência? 
Dessa forma, a pesquisa apresentada está organizada em tópicos que trazem aspectos sobre o ambiente onde a proposta foi desenvolvida, reflexões sobre o ensino remoto e o modelo híbrido, a descrição de como o trabalho foi executado e as informações obtidas a partir disso, considerando o processo de ensino e aprendizagem dos sujeitos envolvidos.

\section{O AMBIENTE DE DESENVOLVIMENTO DA PROPOSTA}

O plano de ensino para o formato remoto "A Paisagem: elementos e mudanças", foi desenvolvido no período de 03 a 07 de julho de 2020, na turma do $3^{\circ}$ ano "C" do Ensino Fundamental, Anos Iniciais, em uma escola da rede municipal de ensino de São Bento- PB (Figura 1).

Figura 1: Mapa de localização da escola campo de pesquisa no município de São Bento - PB.

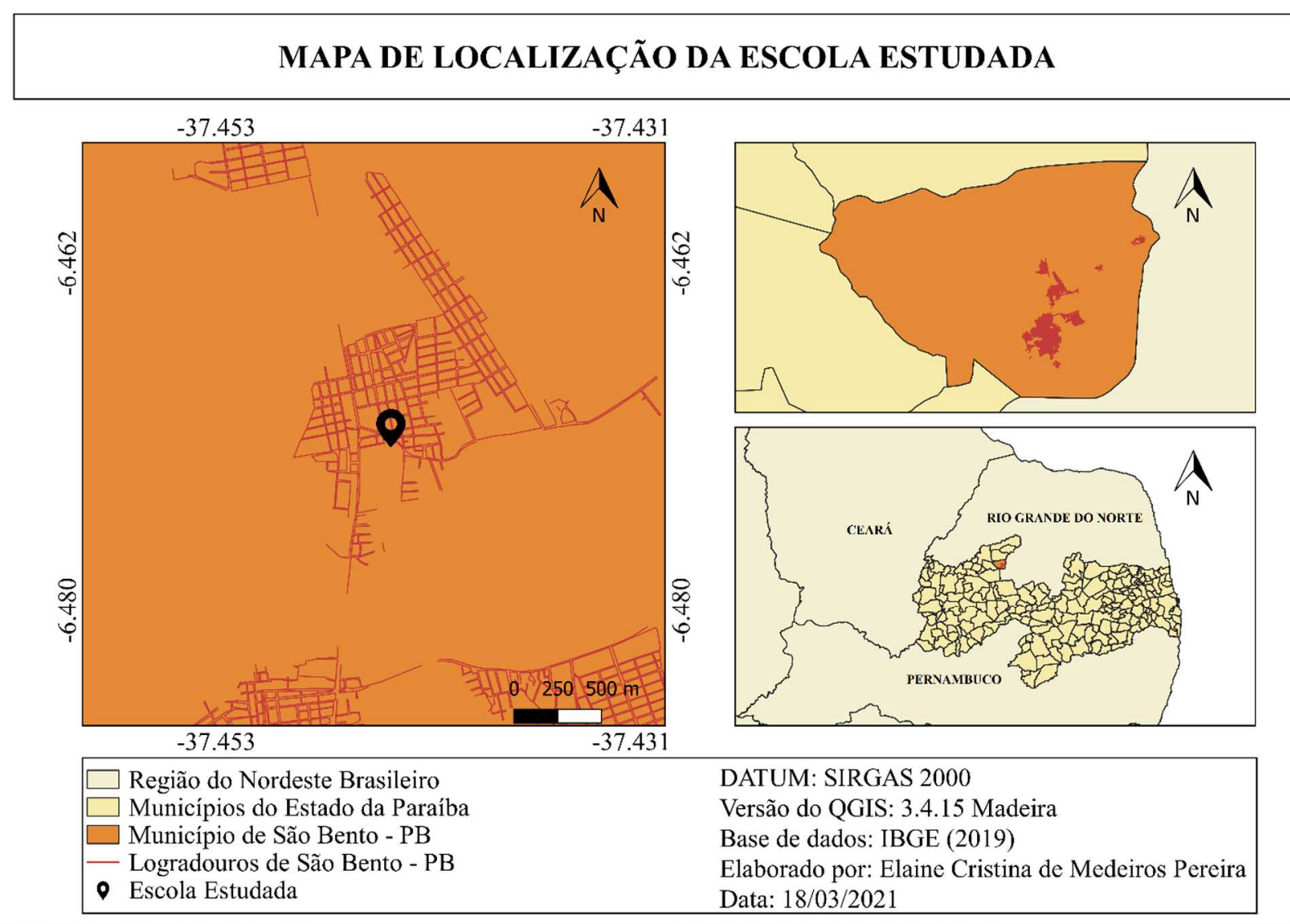

Fonte: Elaborado pelos autores, 2021.

A pesquisa foi realizada no ano de 2020 e nesse contexto, a escola ofertou a Educação Infantil, com os níveis 4 e 5 e o Ensino Fundamental Anos Iniciais, nos turnos matutino e vespertino. Além disso, foi oferecido turmas vinculadas a Educação de Jovens e Adultos (EJA) 
no turno noturno para os Anos Iniciais e Finais do Ensino Fundamental. Com isso, a instituição contando com aproximadamente 1.299 alunos matriculados, provenientes das zonas rural e urbana deste município.

Considerando os aspectos históricos dessa instituição de ensino, a partir das informações contidas no Projeto Político Pedagógico (PPP), podemos destacar que a escola foi edificada, no ano de 1988, em um bairro periférico da cidade, onde inicialmente era conhecido por "Areia Fina”. Sua construção se deu através da lei de autorização $n^{\circ} 145 / 97$ e do projeto de lei $n^{\circ}$ 293/90. O terreno para obra foi doado a prefeitura pela pessoa de Florêncio Cândido Ramalho, morador daquela localidade.

Atualmente, a equipe administrativa e pedagógica dessa instituição de ensino é formada por uma diretora, com graduação em Pedagogia e três diretores adjuntos que desempenham funções nos turnos matutino, vespertino e noturno. O grupo de trabalho ainda consta com uma supervisora pedagógica, com formação em pedagogia e especialista na área de atuação e duas secretárias.

Dos professores que atuam na instituição durante os horários matutino, apenas um está em processo de formação (graduação), já o restante é formado na área de atuação. Desse grupo, doze possuem especialização, sendo que, dois já concluíram mestrado e um ainda está cursando. Vale salientar que destes profissionais apenas quatro são contratados, os demais estão em sala de aula por meio de concurso público.

Em relação aos professores que atuam na EJA é importante destacar que nenhum dos profissionais são efetivos. Para desempenhar essa função, a rede municipal de ensino realiza um processo seletivo anualmente e os requisitos exigidos é que o candidato possua curso de formação no campo de trabalho, ou que pelo menos esteja cursando. Dessa maneira, nem todos são formados na área de atuação, onde alguns possuem graduação nas licenciaturas e/ou pedagogia e outros ainda estão em processo de conclusão do curso.

A análise documental permitiu identificar que o Projeto Político Pedagógico (PPP) da instituição apresenta-se fundamentado nas concepções e finalidades da educação escolar brasileira, definidas na Constituição Federal, na Lei de Diretrizes e Bases da Educação Nacional (LDB no 9.394/96), nos Parâmetros Curriculares Nacionais (PCNs) e nas Diretrizes Curriculares Nacionais da Educação Básica, onde sua última atualização se deu no ano de 2018. 
Além disso, para a escrita do manuscrito foi considerado ainda o Estatuto da Criança e do Adolescente/ECA, a resolução do Conselho Municipal de Educação (CME), as Leis 10.639/03 e 11.645/08 que tornam obrigatório, o ensino de história e cultura africana/afrobrasileira e indígena na educação básica, o projeto de Lei do Senado ${ }^{\circ} 429$, de 2003 que institui o Estatuto da Pessoa com Deficiência, como também, a Lei $n^{\circ} 10.741$, de $1^{\circ}$ de outubro de 2003 , que estabelece o Estatuto do Idoso. Entretanto, algo que não foi contemplado na elaboração desse instrumento legal foi as orientações dadas pela Base Nacional Comum Curricular (BNCC), o que carece de uma reformulação urgente. Em se tratando do trabalho pedagógico desenvolvido na escola, consta no PPP que seu maior compromisso está vinculado a:

Garantir ao educando a oportunidade de comprovar suas ideias pelos resultados de
sua aplicação prática, para assim, compreender melhor o seu sentido e descobrir o real
valor para a vida. [...] visando à formação integral do cidadão conhecedor dos seus
direito e deveres, sendo funcionários, alunos e pais com a capacidade de se posicionar
criticamente perante a sociedade em que vive. Assim despertar-se para a formação de
uma consciência crítica do educando, afim de que ele seja formador de opiniões e
capaz de lutar pelos seus direitos e deveres respeitando seu próximo (PPP, 2018, p.27).

Isso mostra que a escola tem delineado um papel pedagógico com objetivos na formação dos seus estudantes, caracterizando-se como uma instituição pública de ensino com legitimidade para conferir educação escolar com responsabilidade social.

\section{O FORMATO DE ENSINO REMOTO EMERGENCIAL E O AMBIENTE CAMPO DE PESQUISA}

Devido a atual situação vivenciada no Brasil e no mundo em relação ao contexto da pandemia, passamos a adequar nossa rotina de vida a uma nova realidade. O distanciamento e o isolamento social imposto como forma de controlar e/ou amenizar proliferação do vírus, fez com que diversas atividades do nosso cotidiano fossem modificadas.

Nas instituições educacionais, por exemplo, novos desafios surgiram e por isso, professores tiveram que se adaptar à realidade para atender as demandas exigidas e cumprir com suas obrigações, para que as atividades escolares não fossem interrompidas.

A vivência presencial na sala de aula mudou e os encontros passaram a ser realizados mediante o ensino remoto emergencial, considerando os equipamentos tecnológicos disponíveis e a realidade dos sujeitos envolvidos nessa ação. 
O ensino remoto é uma possibilidade emergencial que mantém o distanciamento entre professor e aluno assim podendo evitar a contaminação do vírus COVID-19, mesmo com os problemas técnicos operacionais que são decorrentes, visando um atendimento rápido e adequado, considerando a situação vivenciada e as exigências educacionais.

Mesmo sendo mediado por tecnologia, esse formato de ensino diverge da modalidade de ensino a distância e se adequa as orientações disponibilizadas por estado e municípios. A Educação a Distância (EAD) é desenvolvida através de um ambiente virtual próprio, fundamentada por um pensamento teórico-metodológica específico, com a disponibilização de aparatos didático-pedagógico e apoio profissional (tutores). Enquanto isso, o ensino remoto se estabelece através de plataformas educacionais ou outros meios que até então possuíam funcionalidades distintas, mas que por estarem acessíveis ao público, também permitem a distribuição de informações e conteúdos educacionais (GARCIA [et al], 2020).

Dessa maneira, o ensino remoto não possui um padrão metodológico, o que permite ao professor ter autonomia na hora de elaborar sua proposta pedagógica. Assim, o docente tem a oportunidade de mediar suas aulas fazendo uso de ferramentas, aplicativos e software que estejam a sua disposição e do estudante. (GARCIA et al., 2020).

Para essa situação emergencial, o professor necessita de um planejamento que possibilite atender as demandas exigidas de forma rápida e eficaz. Por isso, deve ser organizado de forma objetiva, funcional e que apresente percursos diversificados, considerando a realidade do aluno e do professor, as estratégias didáticas e os recursos tecnológicos disponíveis. (MORAIS et al., 2020).

Isso implica dizer, que no contexto educacional de ensino, esse planejamento estratégico pode atribuir dois sentidos. O primeiro, possui sustentação nas tecnologias digitais e depende do acesso a aparatos e recursos de mídias e suporte. Já o segundo, se estabelece a partir de práticas inovadoras, onde sua descrição irá necessitar de um recurso, que tanto pode ser analógico como digital. Vale salientar que essas práticas demonstram aspectos metodológicos considerando o saber-fazer do docente ao invés de valorizar a forma ou o que irá ser usado para desempenhar essa função. (GARCIA et al., 2020).

Dessa maneira, ao planejar uma proposta para ensino em circunstância emergencial, o professor precisa ter consciência do que é ensinar de forma remota, e a partir disso estabelecer 
as competências e habilidades necessárias para que o aluno aprenda. Além disso é fundamental que esse profissional reconheça os princípios básicos que constituem a aprendizagem no ensino remoto. (GARCIA et al., 2020).

Em virtude da nova realidade imposta, estados e municípios precisaram reorganizar os calendários escolares e em função do ensino remoto. Assim como em diversas instituições, a escola campo de pesquisa passou a seguir orientações do documento elaborado pela Secretaria Municipal de Educação para atender as necessidades exigidas nesse período de isolamento social.

A Emenda as Diretrizes Operacionais para o Funcionamento das Escolas Municipais de São Bento/2020, foi organizada e disponibilizada para todos os profissionais da educação e a partir disso, o documento passou a servir de base para a elaboração e planejamento das atividades educacionais. Dessa forma, quando se trata da reorganização do calendário escolar e das propostas pedagógicas para o ensino remota, podemos destacar:

Art. $1^{\circ}$ A Rede Municipal de Ensino de acordo com toda legislação vigente, implementa o ensino remoto após reorganização do calendário e elaboração do Plano Estratégico Emergencial de cada Unidade Escolar para execução no decurso do distanciamento social devido a pandemia do Covid-19.

Art. $2^{\circ}$ - Reorganizar o calendário escolar visando a garantia da realização de atividades escolares não presenciais para fins de atendimento aos objetivos de aprendizagem previstos no currículo das etapas - Educação Infantil e Ensino Fundamental e modalidades: Educação de Jovens e Adultos - EJA, Educação Especial por meio do AEE, Educação do Campo e Quilombola - cumprindo o disposto na legislação e normas correlatas sobre o respeito da carga horária letiva mínima estabelecida pela LDB, nos seguintes termos:

I - Serão trabalhadas no ensino remoto uma carga horária diária de 04 (quatro) horas com a realização de atividades pedagógicas não presenciais (mediadas ou não por tecnologias digitais de informação e comunicação);

II - A realização de atividades pedagógicas não presenciais (mediadas ou não por tecnologias digitais de informação e comunicação) enquanto persistirem restrições sanitárias para presença de estudantes nos ambientes escolares, garantirão a carga horária exigida na legislação vigente e ainda, garantirão o cumprimento de competências e habilidades contidas na Base Nacional Comum Curricular - BNCC através do currículo elaborado para o ano letivo/2020, e contemplarão temas relativos a pandemia do Covid-19;

III - Adoção de material didático remoto ou impresso com orientações pedagógicas distribuídas semanalmente aos alunos, seus pais ou responsáveis, com a orientação (videoaulas, conteúdos organizados em plataformas virtuais de ensino e aprendizagem, redes sociais, correio eletrônico, blogs, entre outros); e pela adoção de material didático impresso;

IV - Realização de atividades on-line síncronas, regulares em relação aos objetos de conhecimento, de acordo com a disponibilidade tecnológica;

V - Oferta de atividades on-line assíncronas regulares em relação aos conteúdos, de acordo com a disponibilidade tecnológica e familiaridade do usuário;

VI - Os estudantes que não realizarem as atividades não presenciais ou apresentarem 
maiores dificuldades de aprendizagem, deverão ser encaminhados à recuperação e reforço para a consolidação de aprendizagens essenciais para seu percurso educacional no retorno às aulas presenciais;

VII - Em havendo necessidade, poderão ser atribuídas aulas a professores que desejarem realizar composição ou complementação de sua carga horária de trabalho, ou contratados professores para a realização das atividades adicionais de recuperação a fim de garantir a aprendizagem dos alunos durante o período de aulas presenciais, conforme instrução a ser editada ${ }^{1}$.

Dessa forma, a reorganização do calendário escolar e as propostas pedagógicas retratadas anteriormente, permitiu que os profissionais da educação, que atuam nesse município, tivessem acesso a procedimentos, direcionamentos e normas que precisavam ser seguidas durante esse momento de pandemia. Por meio disso, as instituições de ensino tiveram a oportunidade de organizar seu trabalho, possibilitando estratégias que colaborem para que as atividades escolares não fossem interrompidas ou tivessem grandes perdas.

Portanto, esse aparato legal oferece apoio para que as escolas desempenhem o trabalho administrativo e pedagógico adequado a realidade vivenciada e ao mesmo tempo contribua para o progresso da aprendizagem do aluno.

\section{O ENSINO HÍBRIDO, ALGUMAS REFLEXÕES IMPORTANTES}

Para o desenvolvimento dessa proposta foi adotado o modelo metodológico vinculado ao ensino híbrido, no formato remoto. Isso implica dizer que as atividades foram desenvolvidas por meio de encontros síncronos entre professor(a) e alunos e atividades assíncronas. As aulas on-line aconteceram através do aplicativo Google Meet, com dia e hora marcados. Já as tarefas off-line foram propostas em um cronograma e disponibilizadas de maneira impressa e pelo grupo de um aplicativo de celular. $\mathrm{O}$ detalhamento dos passos percorridos por essa atividade virá posteriormente na discussão escrita desse texto, mas antes disso é fundamental refletir a respeito do método de ensino que sustentou o seu planejamento e execução.

O ensino híbrido consiste em uma proposta metodológica que se caracteriza pela combinação de possibilidades para promover melhorias na qualidade do ensino. Diferente do modelo tradicional, o formato híbrido oferece oportunidade de se aprender e ensinar dentro ou

\footnotetext{
${ }^{1}$ Informações retiradas da Emenda as Diretrizes Operacionais para o Funcionamento das Escolas Municipais de São Bento/2020.
} 
fora do espaço escolar, tanto de maneira formal, quanto informal. (BACICH; TANZI NETO; TREVISAN, 2015).

Esse método tem como base os valores, as competências e habilidades, as metodologias ativas e a personalização do ensino, considerando a realidade vivenciada e a colaboração a partir das tecnologias digitais. (BACICH; TANZI NETO; TREVISAN, 2015).

Essa proposta pode ser integrada na prática da sala de aula em qualquer realidade. $\mathrm{O}$ ensino híbrido colabora para a autonomia do educando em relação ao seu processo de aprendizagem. Nesse contexto, a combinação metodológica que dá alicerce a esse ensino, pode ser desenvolvido de diversas maneiras e nos mais diferentes ambientes. Além das estratégias utilizadas pelo professor no cotidiano da sala de aula, as tecnologias digitais servirão de suporte para que haja a promoção do ensino e a interação entre alunos dentro e fora do espaço físico da escola, havendo assim, trocas de experiências e conhecimento. Dessa maneira, ao ter domínio dessa informação, o docente tem a oportunidade de refletir sobre sua prática e buscar introduzir ou aprimorar propostas inovadoras em suas aulas, considerando os mecanismos metodológicos e tecnológicos disponíveis em sua realidade com o intuito de colaborar para o progresso educacional do aluno. (BACICH; TANZI NETO; TREVISAN, 2015).

Sendo assim, o ensino híbrido traz uma proposta didático pedagógica que presa pela personalização do ensino, isso quer dizer que o professor deve entender que a educação e consequentemente sua prática não deve ser padronizada, mas sim, desempenhada com o foco no progresso individual do aluno, já que cada um tem um tempo e uma forma específica para aprender. Isso mostra que o docente deve respeitar as condições específicas de cada educando e potencializar sua aprendizagem fazendo uso dos recursos tecnológicos. (BACICH; TANZI NETO; TREVISAN, 2015).

\section{RESULTADOS E DISCUSSÕES OBTIDOS A PARTIR DA EXECUÇÃO DA PROPOSTA}

Antes de descrever as etapas de desenvolvimento dessa proposta e os resultados obtidos com essa ação é fundamental relatar alguns aspectos sobre a realidade onde o trabalho foi executado. 
A turma onde a atividade foi aplicada é o $3^{\circ}$ ano "C" do Ensino Fundamental, Anos Iniciais, de uma escola pública da rede municipal de ensino de São Bento - PB. O grupo de estudantes é composto por vinte e oito (28) alunos matriculados, sendo dezessete (17) meninas e onze (11) meninos. Essas crianças são provenientes da área onde a instituição se encontra e/ou bairros vizinhos.

Como de costume, no ato da matrícula é feito uma triagem pela secretaria da escola. Familiares e/ou responsáveis pelas crianças disponibilizam informações como, números de telefones e endereço, que são repassados para os professores no início do ano letivo. Para facilitar a comunicação, fica a critério do docente criar um grupo em um aplicativo de troca de mensagens (WhatsApp), caso sinta necessidade, ou contactar essas pessoas através de ligação.

Vale salientar que nem todos os responsáveis pelas crianças disponibilizaram essa informação. De acordo com os dados repassados pela secretaria da instituição, do total de alunos matriculados em 2020, aproximadamente $87 \%$ das famílias compartilharam um número de telefone no ato da matricula. Destes, cerca de 53\% tinham acesso ao aplicativo de mensagens. Com o agravamento da situação provocada pelo COVID-19 e a possível adesão ao isolamento social, nos últimos dias de aula presencial, professores e gestão fizeram uma busca para conseguir os contatos dos alunos que faltavam.

O que não esperávamos, é que, com o isolamento social, esse instrumento passasse a ser nosso maior meio de interação, tanto para tratar assuntos individuais e coletivos da turma, como também, para auxiliar na execução das aulas no formato remoto e acompanhar o processo de ensino e aprendizagem dos educandos, já que este faz parte da realidade de todos.

É fundamental destacar que todos os alunos possuem acesso à internet, porém, precisam fazer uso do smartfone dos pais e familiares, pois não possuem um aparelho próprio. Por esse motivo, optou-se em fazer uso de estratégias que viessem atender as especificidades existentes na realidade onde a atividade foi desempenhada. Assim, para uma sustentação didáticometodológica, pensou-se em uma proposta ancorada nas concepções do ensino híbrido. E por mais que o aplicativo WhatsApp não seja uma plataforma educacional, esse mecanismo está acessível a todos os estudantes e permite que haja o compartilhamento de informações e conteúdos escolares, necessário para que haja o desempenho de cada etapa de execução dessa ação. 
Assim, a sequência didática "A Paisagem: elementos e mudanças", foi organizada a partir do conteúdo programático do currículo de Geografia para o $3^{\circ}$ ano do Ensino Fundamental, presente no livro didático adotado pela instituição e com base na proposta metodológica vinculada ao ensino híbrido. Para o desenvolvimento dessa ação, considerou-se ainda, as orientações dadas pela Emenda as Diretrizes Operacionais para o Funcionamento das Escolas Municipais de São Bento/2020. O intuito dessa proposta foi de apresentar ao educando o conceito de paisagem, os elementos que a compõe e suas transformações, baseado na observação do seu lugar de vivência.

Entretanto, para o desenvolvimento dessa atividade pedagógica, necessitou-se de um período prévio de estudos, essencial para a elaboração do planejamento das ações. Em relação a isso, Silva (2013) enfatiza que é primordial que o professor reflita sobre o que será desempenhado, considerando sua colocação e a do público para quem irá mediar a aula. Dessa forma, essa prática colabora para que o profissional busque por mecanismos que possam colaborar para que o educando tenha interesse em participar do momento.

Então, na aula que antecedeu o primeiro encontro, foi lançado um desafio para turma pelo grupo WhatsApp, no qual, os alunos foram orientados a realizar uma pesquisa no dicionário físico e/ou online, para identificar o significado da palavra paisagem e apresentar o que eles entenderam na aula seguinte. Essa prática tem feito parte da rotina da turma, principalmente quando se apresenta ou aparece palavras desconhecidas para os educandos, nos conteúdos estudados. Na ocasião ainda foi disponibilizado o cronograma (Figura 2) com as atividades sugeridas para a semana posterior. 
Figura 2: Cronograma semanal de Geografia para o $3^{\circ}$ ano "C"

\begin{tabular}{|c|c|c|c|c|}
\hline \multicolumn{5}{|c|}{ CRONOGRAMA SEMANAL DE GEOGRAFIA - DE 03 A 07 DE AGOSTO DE 2020} \\
\hline $\begin{array}{l}\text { DIAS DA } \\
\text { SEMANA }\end{array}$ & $\begin{array}{l}\text { ATIVIDADE } \\
\text { SÍNCRONA }\end{array}$ & $\begin{array}{l}\text { ACOMPANHAMENTO PELO } \\
\text { WHATSAPP }\end{array}$ & ATIVIDADES ASSÍNCRONAS & $\begin{array}{l}\text { DATAS PARA } \\
\text { RETORNO DAS } \\
\text { ATIVIDADES }\end{array}$ \\
\hline $\begin{array}{l}\text { Segunda } \\
(03 / 07)\end{array}$ & $\begin{array}{l}\text { Aula on-line pelo } \\
\text { aplicativo do Google } \\
\text { Meet, das } 14 \text { as } 15 \mathrm{~h} \text {. }\end{array}$ & $\begin{array}{l}\text { Após o encontro síncrono: Orientação sobre } \\
\text { o assunto estudado e atividades propostas na } \\
\text { aula on-line. Momento para tirar dúvida e } \\
\text { realizar atendimento individual. }\end{array}$ & $\begin{array}{l}\text { Tarefa no livro didático presente entre } \\
\text { as páginas } 10 \text { e } 15 \text {. }\end{array}$ & $\begin{array}{l}\text { Enviar foto da atividade } \\
\text { pronta (pelo WhatsApp, } \\
\text { no privado da } \\
\text { professora) até o dia } 07 \\
\text { de agosto. }\end{array}$ \\
\hline Terça $(04 / 07)$ & - & $\begin{array}{l}\text { Vídeo explicativo sobre o assunto e } \\
\text { atividade proposta no encontro on-line. } \\
\text { Vídeo do YouTube para ajudar na } \\
\text { explanação do assunto. Momento para tirar } \\
\text { dúvida e realizar atendimento individual. }\end{array}$ & $\begin{array}{l}\text { Informações disponibilizadas no grupo } \\
\text { do WhatsApp e a tarefa no livro } \\
\text { didático presente entre as páginas } 10 \mathrm{e} \\
15 \text {. }\end{array}$ & $\begin{array}{l}\text { Enviar foto da atividade } \\
\text { pronta (pelo WhatsApp, } \\
\text { no privado da } \\
\text { professora) até o dia } 07 \\
\text { de agosto. }\end{array}$ \\
\hline Quarta (05/07) & - & $\begin{array}{l}\text { Video explicativo sobre o assunto e } \\
\text { atividade proposta no encontro on-line. } \\
\text { Momento para tirar dúvida e realizar } \\
\text { atendimento individual. }\end{array}$ & $\begin{array}{l}\text { Informações disponibilizadas no grupo } \\
\text { do WhatsApp e a tarefa no livro } \\
\text { didático presente entre as páginas } 10 \text { e } \\
15 \text {. }\end{array}$ & $\begin{array}{l}\text { Enviar foto da atividade } \\
\text { pronta (pelo WhatsApp, } \\
\text { no privado da } \\
\text { professora) até o dia } 07 \\
\text { de agosto. }\end{array}$ \\
\hline Quinta (06/07) & $\begin{array}{l}\text { Aula on-line pelo } \\
\text { aplicativo do Google } \\
\text { Meet, das } 14 \text { as } 15 \mathrm{~h} \text {. }\end{array}$ & $\begin{array}{l}\text { Após o encontro sincrono: Orientação sobre } \\
\text { o assunto estudado e atividades propostas na } \\
\text { aula on-line. Momento para tirar dúvida e } \\
\text { realizar atendimento individual. }\end{array}$ & $\begin{array}{l}\text { Informações disponibilizadas no grupo } \\
\text { do WhatsApp; tarefa no livro didático } \\
\text { presente entre as páginas } 16 \text { e } 21 \text {; } \\
\text { atividade impressa; produção do cartaz } \\
\text { e vídeo explicativo. }\end{array}$ & $\begin{array}{l}\text { Enviar foto (pelo } \\
\text { WhatsApp, no privado } \\
\text { da professora) da } \\
\text { atividade do livro até o } \\
\text { dia } 10 \text { de agosto; da } \\
\text { atividade impressa até } \\
\text { dia } 11 \text { de agosto. }\end{array}$ \\
\hline Sexta $(07 / 07)$ & - & $\begin{array}{l}\text { Video explicativo sobre o assunto e } \\
\text { atividade proposta no encontro on-line. } \\
\text { Momento para tirar dúvida e realizar } \\
\text { atendimento individual. }\end{array}$ & $\begin{array}{l}\text { Informações disponibilizadas no grupo } \\
\text { do WhatsApp; tarefa no livro didático } \\
\text { presente entre as páginas } 16 \text { e } 21 \text {; } \\
\text { atividade impressa; produção do cartaz } \\
\text { e video explicativo. }\end{array}$ & $\begin{array}{l}\text { Entrega dos registros da } \\
\text { produçâo do cartaz até o } \\
\text { dia } 14 \text { de agosto. }\end{array}$ \\
\hline
\end{tabular}

Fonte: Elaborado pelos autores, 2020.

Para Franco (2015), desafiar o aluno é um mecanismo que permite despertar seu interesse em relação ao conteúdo estudado. As situações que os provocam são as mesmas que corroboram para o retorno em forma de produções. Dessa maneira, as experiências e interações que envolvem as vivências atuais e as interpretações instigadas pelos desafios dados pelo docente propiciará a construção do conhecimento.

O primeiro encontro para discussão da temática se deu no dia 03 de agosto de 2020, por meio de uma aula expositiva e dialogada, de forma síncrona, através da ferramenta Google Mett. Tendo em vista o período que estamos vivendo de distanciamento, optou-se em fazer uso desse mecanismo, pois ele permite a comunicação por vídeo, propiciando um contato e aproximação em tempo real entre o professor e alunos.

Para apresentação do assunto, optou-se pela exposição de slide, organizado pela professora, contendo palavras-chave, textos curtos, questionamentos e imagens, relacionados ao tema estudado. Na ocasião iniciou-se a discussão do conceito de paisagem, tendo como base os aspectos trazidos pelos estudantes após a pesquisa no dicionário e aquilo que eles conheciam a respeito da temática.

Para Libâneo (1994), esse tipo de prática permite que haja a aproximação do educando com o conteúdo estudado. Dessa maneira, o professor deve propor condições de mediar o educando em relação ao que está sendo estudado, considerando sempre suas condições de 
origem. Isso implica dizer que os meios utilizados para essa aproximação, como a organização do ensino, os saberes e métodos pedagógicos são fundamentais para a construção da aprendizagem do aluno.

O uso de imagens também fez parte do primeiro encontro, para isso, foi selecionado algumas paisagens retiradas da internet. Essa ação servil para exercitar a percepção das crianças e a interpretação em relação aos elementos naturais e culturais existentes em cada uma delas. Para finalizar esse primeiro momento, os estudantes foram orientados a realizar a atividade propostas no livro de Geografia (ente as páginas 10 - 15).

É importante destacar que as aulas no formato remoto (síncronas), acontecem no mesmo horário das aulas presenciais, ou seja, à tarde. Tendo em vista que muitas crianças usam os celulares dos pais ou responsáveis para participar desses momentos, isso implica dizer que em algumas situações poderá acontecer a indisponibilidade do aparelho tecnológico na ocasião proposta.

No primeiro encontro contamos apenas com a presença de aproximadamente $30 \%$ da turma e em relação a interação dos alunos nessa atividade, podemos destacar que houve uma participação significativa. Dos oito estudantes, apenas um não fez a pesquisa no dicionário, mas isso não o impediu de expor seu conhecimento. Cada um com seu jeito, destacou aquilo que conhecia a respeito da temática, trazendo sempre exemplos de sua realidade. Isso ficou claro principalmente quando tratamos sobre os elementos que compõem a paisagem, onde eles fizeram questão de destacar esses aspectos vistos nas imagens da apresentação em slide e relacionar com a paisagem do seu lugar de vivência.

Com o intuito de atender aos que não estiveram presentes na aula on-line, os dias 04 e 05 de agosto, ficaram reservados para orientação e detalhamento dos assuntos apresentados no encontro síncrono, bem como, as atividades sugeridas. Para isso, foi necessário a elaboração de vídeos curtos com uma breve explanação do conteúdo estudado e a mediação das atividades sugeridas pelo livro didático a serem realizadas. O material áudio visual foi produzido pela professora, seguindo a mesma dinâmica da apresentação de slide e ofertado no grupo do WhatsApp. Além disso, encaminhou-se o link do vídeo "Paisagem: elementos naturais e culturais!", presente no YouTube, que trata sobre o conceito de paisagem, os elementos que a compõem e as transformações ocorridas através das alterações naturais e humanas. Tais 
materiais foram disponibilizados para todos, com o intuito de contribuir para a construção do conhecimento do educando.

Sendo assim, disponibilizar essas informações por meio do mecanismo citado anteriormente, consiste em uma proposta que visa atender a todos os discentes, principalmente os que estiveram ausentes no momento de interação pelo Google Meet. Com isso, o aluno terá acesso ao que foi discutido, de acordo com o seu tempo disponível, sem haver grandes prejuízos.

Partindo desse pressuposto, Cavalcante (2017), considera que o processo de ensino da Geografia Escolar, deve ser organizado através de metodologias que permitam aos alunos a consolidação dos objetivos proposto no que foi planejado pelo professor. Sendo assim, o percurso metodológico é visto como um conjunto de procedimentos didáticos, organizados a partir de métodos e técnicas, usados pelos docentes para alcançar os propósitos de ensino e aprendizagem, de forma eficaz.

Em se tratando da interação dos alunos com as atividades assíncronas disponibilizadas no WhatsApp, podemos destacar que houve uma participação considerável. Do total de matriculados, aproximadamente $63 \%$ acessou aos vídeos e realizou a tarefa do livro no tempo proposto. Os demais, foram realizando ao longo da semana, dando retorno dos registros como solicitado, porém, para que isso acontecesse, existiu casos em que a professora precisou fazer chamadas de vídeo ou voz para atender individualmente as crianças que apresentaram dúvidas ao responder as atividades ou por não ter quem as acompanhasse em casa, durante essa etapa.

Já no dia 06 de agosto aconteceu o segundo encontro síncrono, usando novamente a ferramenta do Google Meet. Na ocasião foi realizada uma aula expositiva e dialogada sobre as transformações da paisagem, com auxílio de uma apresentação em slide organizada pela professora. Iniciou-se o momento retomando o que havia sido discutido anteriormente, ressaltando o conceito de paisagem e os elementos que as compõem. O material de projeção contou com textos curtos e fotografias (antigas e recentes) de locais do município de São Bento - PB. As imagens foram retiradas da internet, e como exemplo, podemos destacar: a construção da ponte sobre o rio Piranhas (Figura 3), o mercado público, a prefeitura municipal e a rua "Velha", espaço de formação da cidade em destaque. 
Figura 3: Construção da ponte sobre o Rio Piranhas, São Bento - PB

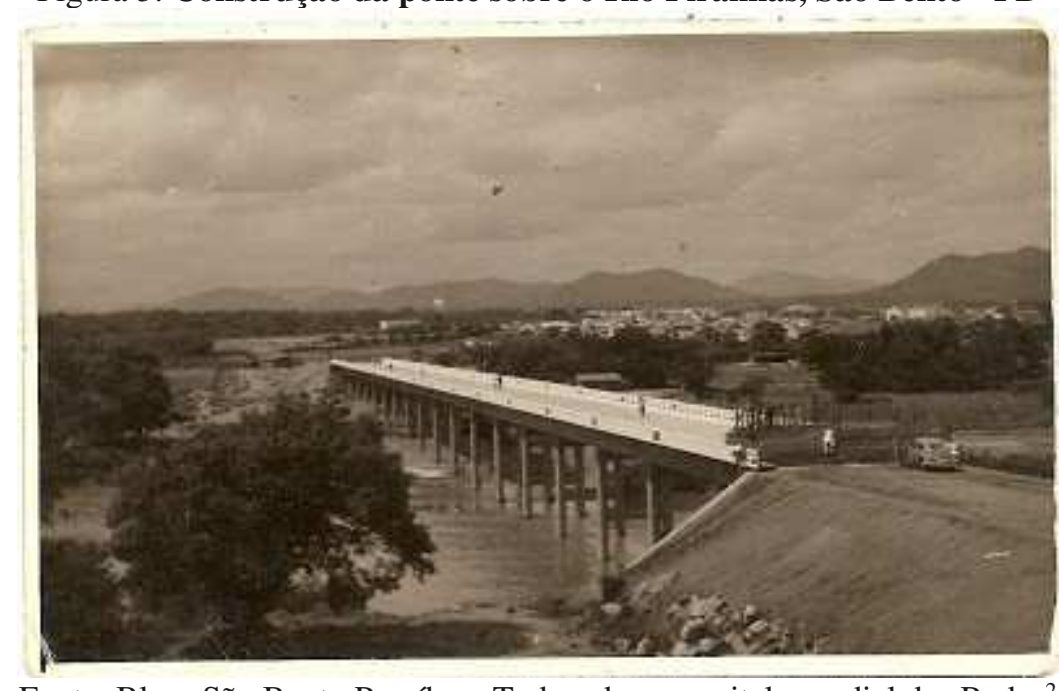

Fonte: Blog: São Bento Paraíba - Tudo sobre a capital mundial das Redes ${ }^{2}$

A exposição das fotografias deu oportunidade para que alunos fizessem a observação da paisagem de outrora do seu lugar de vivência, possibilitando assim, a reflexão em relação as transformações ocorridas ao longo do tempo. Ao apresentar as fotos, foi feito questionamentos sobre a temática, dentre os quais pode-se destacar: Quais os elementos naturais e culturais vocês conseguem observar nessas paisagens? Porque será que a ponte foi construída? A rua "Velha" continua do mesmo jeito? O que mudou? A prefeitura e o mercado permanecem como nas fotos da época de construção? Portanto, o intuito dessa etapa era identificar a interação e percepção dos alunos em relação aos elementos, bem como, as mudanças ocorridas na paisagem do lugar em que vivem.

Na Geografia Escolar, ações como essa permite a explanação de conteúdos e a sua conexão com diferentes situações do cotidiano do aluno. Isso pode possibilitar que este indivíduo problematize os diversos espaços materializados e compreendidos na perspectiva das abordagens conceituais próprios da ciência geográfica, ligados, ao lugar, a paisagem, ao território e a região, podendo assim, estabelecer conexões entre o presente e o passado, o geral e o específico, as atuações individuais e as coletivas em relação as distintas escalas geográficas. Além do mais, permiti que o estudante tenha a oportunidade de ler e explicar os lugares e as

\footnotetext{
${ }^{2}$ Disponível em: <http://saobentoparaiba.blogspot.com/2012/06/fotos-do-tunel-do-tempo.html〉. Acesso em: 01 ago. 2020.
}

Pereira; Garcia, 2021 
paisagens, bem como, entender que ele pode atuar em seus espaços de vivência com uma perspectiva mais crítica. (THIESEN, 2011).

Em se tratando da participação no segundo encontro síncrono, foi possível destacar que não foi tão diferente do primeiro. Apenas $30 \%$ (aproximadamente) dos alunos que compõem a turma estavam presentes na ocasião. Entretanto, a interação na discussão do conteúdo estudado foi valiosa. Os questionamentos feitos durante a explanação do assunto sobre o que eles conseguiram identificar a partir da comparação das imagens, proporcionou que os educandos conseguissem não só identificar os elementos e as transformações, mas também, relacionar o que estava sendo estudado, com a sua realidade.

Isso implica dizer, que ao possibilitar que o aluno observe e perceba o espaço geográfico do seu lugar de vivência, o professor estará disponibilizando que este sujeito construa os subsídios necessários para associar os aspectos locais aos globais, dinamizando assim sua aprendizagem. Dessa forma, o educando compreenderá o que é o espaço na Geografia e as relações que existem entre este, a sociedade e os objetos. (CAVALCANTI, 2017).

Para finalizar o momento pelo Google Meet, foi orientado a realização das tarefas assíncronas. A primeira, consiste nas atividades escritas, uma, presente no livro didático, entre as páginas 16 e 21 e a outra entregue pela escola de forma impressa, seguindo o cronograma disponibilizado para a semana. Para a realização dessa proposta, os estudantes precisariam fazer a leitura e interpretação dos textos do livro e responder algumas questões, além disso, deveriam representar a paisagem que estava a sua volta, interpretar as imagens das tarefas e destacar os elementos naturais e culturais em cada uma delas.

Em se tratando da atividade impressa, vale ressaltar que esta é uma das sugestões disponibilizadas pela Emenda as Diretrizes Operacionais para o Funcionamento das Escolas Municipais de São Bento/2020. Dessa forma, a gestão da instituição educacional onde a proposta foi desenvolvida, orienta aos professores que além do acompanhamento pedagógico que acontece pelo WhatsApp, por exemplo, os docentes devem propor atividades impressas para as turmas, principalmente para que os estudantes que não dispõem de acesso à internet, ou celular, sejam incluídos e não tenham grandes prejuízos em relação ao processo de aprendizagem durante o período de isolamento social. Sendo assim, esse material é elaborado 
pelo professor de acordo com o conteúdo estudado, enviado para a supervisão escolar, impresso e entregue todas as quartas-feiras, no horário de aula em que o aluno é matriculado.

Ainda sobre as atividades assíncronas e a sua sistematização, pode-se ressaltar que a segunda proposta correspondeu a produção de um cartaz, onde os alunos foram orientados a observar a paisagem do seu entorno (de uma janela, da porta de sua casa, ou até mesmo de seu quintal) e representar em forma de desenho aquilo que foi apreciado, destacando os elementos naturais e culturais identificados nesse espaço. Assim, ao concluir essa etapa, o estudante deveria fazer um pequeno vídeo explicando sua produção e encaminhar para a professora, juntamente com uma foto do trabalho pronto.

A proposta didático-pedagógica foi finalizada na sexta-feira, sete de agosto. Na ocasião realizou-se o mesmo processo dos dias quatro e cinco, com a disponibilização de vídeos curtos com os aspectos discutidos sobre o assunto e a explicação das atividades sugeridas. Isso permitiu que os estudantes que por alguma eventualidade não pudessem participar do encontro síncrono, tivessem acesso ao detalhamento do que foi estudado durante esse momento e a explanação das atividades sugeridas para serem desenvolvidas ao longo da semana.

Em se tratando da participação dos alunos na realização das atividades propostas, podese destacar que as tarefas escritas foram desempenhadas por todos seguindo as orientações dadas. Já a produção do cartaz e do vídeo explicativo teve um retorno diferente. Nem todos os docentes cumpriram o que foi orientado no período disponibilizado, dos matriculados, somente $52 \%$ realizaram a ação como sugerido, os demais, só fizeram o cartaz após orientação individual da professora e, ao invés do vídeo, alguns estudantes optaram em fazer a explicação de suas produções por meio de áudio, enviados juntamente com a imagem do trabalho concluído.

Vale ressaltar ainda, que além dos encontros síncronos e das informações disponibilizadas no grupo da turma, sobre o conteúdo estudado, foi ofertado um horário para atendimento individual, considerando a ordem de procura e sendo realizado por mensagens de texto, áudios, chamada de vídeo ou voz. O objetivo desse momento era proporcionar o esclarecimento de dúvidas sobre o assunto estudado e as tarefas sugeridas, funcionando assim como uma tentativa de atender melhor as especificidades existentes e acompanhar de perto o processo de aprendizagem de cada aluno. 
Em se tratando do acompanhamento da aprendizagem, podemos destacar que este processo se deu de forma contínua, durante o desenvolvimento da proposta. Para a etapa de aferição, foi observando o que cada aluno entendeu sobre o conceito estudado; se conseguiu identificar que a paisagem é constituída de elementos naturais e culturais; e as reflexões construídas por ele sobre as transformações ocorridas na paisagem do seu lugar de vivência de acordo com o que foi trabalhado. Dessa maneira, a análise em relação a aprendizagem do educando se deu a partir das etapas estabelecidas no processo de avaliação, considerando os elementos e descritores usados para obtenção de informações.

Quando se fala em processo avaliativo, pode-se destacar que esta ação consiste em uma etapa do processo de ensino que permite o professor identificar os caminhos percorridos em relação a aprendizagem do aluno, seus avanços e dificuldades ao longo do percurso, bem como, refletir sobre sua prática. Portanto, as dúvidas, os questionamentos, os acertos e até mesmo os erros dos estudantes devem ser considerados como elementos essências da ação educativa. (HOFFMANN, 2017).

As leituras feitas sobre o método de ensino que deu sustentação para organização dessa proposta, o modelo híbrido, mostrou que as tecnologias podem contribuir para o crescimento intelectual do educando e ao mesmo tempo, ofereceu subsídios para entender a importância de se refletir sobre a prática do professor, considerando a personalização do ensino. Desse modo, planejar uma estratégia didática que se prese pelo crescimento individual do aluno e o respeito as suas dificuldades, requer atenção redobrada também, durante a avaliação. Já que, como parte do processo, a avaliação da aprendizagem deve percorre os mesmos caminhos, pois de nada adianta propor estratégias diversificadas de ensino e continuar utilizando apenas um parâmetro avaliativo para identificar o conhecimento construído pelo educando em relação ao que foi estudado.

Portanto, para obtenção de informações sobre o processo de aprendizagem do estudante, identificou-se o seu desempenho e participação nas atividades propostas. Para isso, foi indispensável a análise do conhecimento prévio de cada aluno através de questionamentos e o levantamento de hipótese por eles elencados. É fundamental destacar que a pesquisa no dicionário sobre o significado da palavra paisagem, deu suporte para essa discussão inicial e uma ponte para o aprofundamento da temática em questão. 
Nessa perspectiva foi considerado ainda a participação do aluno nos encontros síncronos e no grupo do WhatsApp, sua interação e questionamentos sobre o assunto estudado, a interpretação de imagens e textos sobre a temática, bem como, a realização das atividades sugeridas pelo livro e/ou impressa e a elaboração e apresentação do cartaz sobre a paisagem do seu lugar de vivência.

A análise desses elementos foi guiada pelo registro da ficha individual de avaliação (Figura 4), elaborada pela professora. Assim, considerou-se os apontamentos elencados sobre o desempenho de cada aluno em relação ao que foi trabalhado, levando em conta os aspectos positivos e enaltecendo o que precisa de mais atenção em relação a aprendizagem do aluno.

Figura 4: Ficha de avaliação individual do aluno

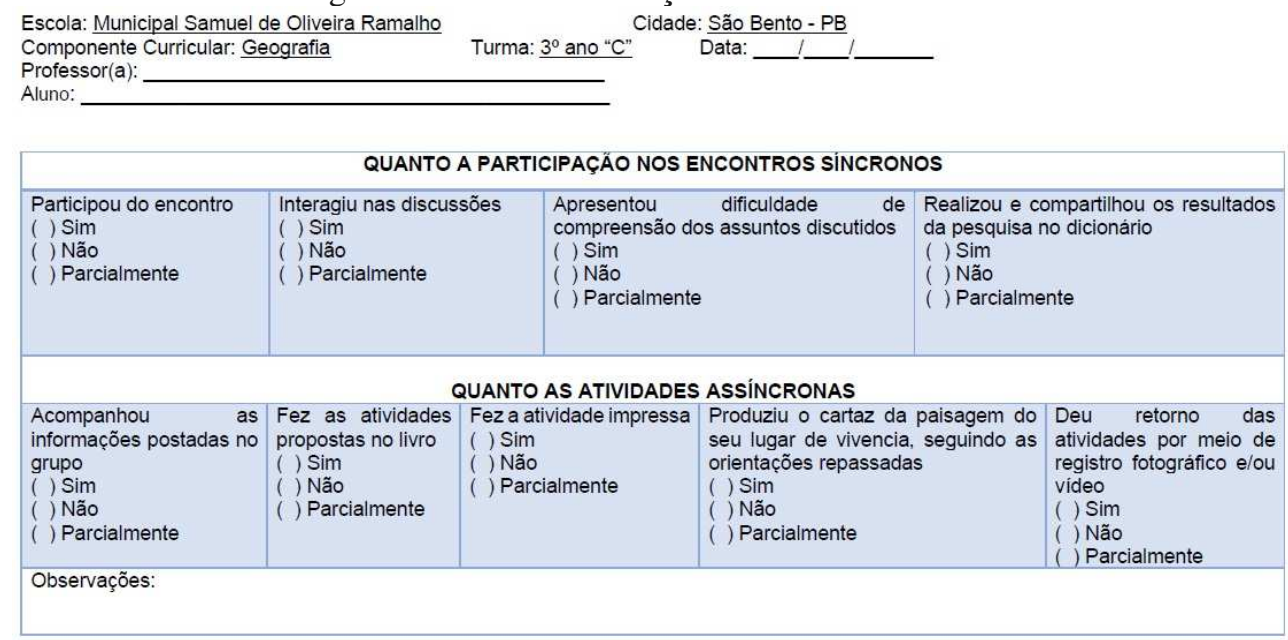

Fonte: Elaborado pelos autores, 2020.

Dessa forma, após a análise e correção de cada atividade, os alunos e suas famílias receberam um feedback de todos os detalhes e informações elencadas sobre esse processo. Dessa maneira, além de acompanhar o progresso da aprendizagem do educando em relação ao conteúdo estudado, os dados obtidos serão fundamentais para que o professor possa comparar a evolução de cada estudante durante o ano letivo de 2020 e refletir sobre sua prática, considerando o que deu certo e o que precisa ser melhorado. 


\section{CONSIDERAÇÕES FINAIS}

Organizar uma proposta de ensino para desenvolver de forma remota e ancorada no ensino híbrido permitiu refletir sobre o papel do professor enquanto mediador do conhecimento, principalmente no que diz respeito ao processo de aprendizagem do aluno nas aulas de Geografia.

Dessa maneira, considerar esse método para fundamentar e organizar uma proposta, no formato remoto, deu espaço e utilização de tecnologias, que muitas vezes não eram usadas nos encontros presenciais, mas que ao ter um direcionamento adequado, contribuiu para o desenvolvimento das aulas, mesmo havendo o distanciamento entro professor e aluno. Portanto, o ensino híbrido nos leva a refletir sobre o quanto o uso das tecnologias pode favorecer no processo de aprendizagem do educando.

Nesse contexto, podemos destacar que a introdução das tecnologias digitais durante as aulas, proporcionou uma ampliação na relação entre professor e aluno, além de contribuir na otimização do tempo de trabalho desse profissional, o que permitiu, um período mais amplo de dedicação na melhoria de suas estratégias de ensino. Para o aluno, essa ação possibilitou que ele deixasse de ser um simples receptor de informações e passasse a ser sujeito atuante na construção do conhecimento, já que este teve a oportunidade de explorar novos caminhos, que estão além das discussões feitas dentro das paredes da sala de aula.

Entretanto, fazer uso de propostas didáticas, vinculadas a métodos de ensino que envolvam as tecnologias digitais não é tarefa fácil, nem algo a ser feito de qualquer forma. Sendo assim, o planejamento é e sempre será o melhor caminho a se percorrer.

Portanto, o desenvolvimento dessa proposta a partir dos encontros síncronos, mesmo que não tendo a participação de todos os estudantes, proporcionou aos envolvidos um contato em tempo real entre professor, alunos e conteúdo, tendo em vista o distanciamento vivenciado durante o período de pandemia. Já a interação e a troca de informações através do WhatsApp, bem como, as demais atividades assíncronas possibilitaram autonomia para o aluno na construção do conhecimento e principalmente na reflexão do professor em relação a sua prática e na importância de se presar por um planejamento didático flexível, tendo como objetivo, o progresso individual de cada educando. 


\section{REFERÊNCIAS}

CAVALCANTI, L. de S. O trabalho do professor de geografia e tensões entre demandas da formação e do cotidiano escolar. In, Conhecimentos da geografia: percursos de formação docente e práticas na educação básica. Belo Horizonte: ICG, 2017. (p. 100-123).

FRANCO, M. A. S. Práticas pedagógicas de ensinar-aprender: por entre resistências e resignações. Educ. Pesqui., São Paulo, v. 41, n. 3, p. 601-614, jul./set. 2015.

BACICH, B.; TANZI NETO A.; TREVISAN, F. de Mello (org). Ensino híbrido: personalização e tecnologia na educação. Porto Alegre: Penso, 2015

GARCIA, T. C. M. [et al]. Ensino Remoto Emergencial: proposta de design para organização das aulas. [recurso digital]. Natal: SEDIS/UFRN, 2020. (Caderno 1).

HOFFMANN, J. Avaliação: mito \& desafio: uma perspectiva construtivista. 45. ed. Porto Alegre: Mediação, 2017.

LIBÂNEO, J. C. Didática. São Paulo: Cortez, 1994. - (Coleção magistério. $2^{\circ}$ grau. Série formação do professor).

MORAIS, I. [et al]. Ensino Remoto Emergencial: orientações básicas para elaboração do plano de aula. [recurso digital]. Natal: SEDIS/UFRN, 2020. (Caderno 2).

SÃO BENTO. Prefeitura Municipal. Secretaria Municipal de Educação. Emenda no 002/2020/CME, de 4 de maio de 2020. Emenda as Diretrizes Operacionais para o

Funcionamento das Escolas Municipais de São Bento/2020, São Bento - Paraíba: Secretaria Municipal de Educação - Concelho Municipal de Educação, 2020. 11p.

Prefeitura Municipal. Secretaria Municipal de Educação. Escola Samuel de Oliveira Ramalho. Projeto Político Pedagógico. São Bento, 2018. 17p.

SILVA, L. R. da. Docência na contemporaneidade: desafios para professores no ensino superior. Revista Primus Vitam - No $5-1^{\circ}$ semestre de 2013.

THIESEN, J. da S. Geografia escolar: dos conceitos essenciais às formas de abordagem de ensino. Geografia Ensino \& Pesquisa, v. 15, n.1, 2011. 